\title{
The Maritime Labour Convention, 2006, as an ally for International Maritime Health Association
}

\section{Rosa María Aguirre Donadío}

Maritime Lawyer and International Labour Organisation Certified Trainer, DCN \& PARTNERS, Panama

On September 15 and 16, 2016, took place in Panama, the Second International Seminar on Maritime Health which focused on the following issue: "MLC Implementation Process, 2006: Its Impact on Health and Safety at Sea". It could be said that there is a symbiosis between the provisions established as mandatory by the Maritime Labour Convention (MLC), 2006 and the issues being investigated and discovered by maritime medicine, with the purpose of preventing and protecting the crew from the potential environmental risks of working inside a vessel.

In this sense, the MLC, 2006 contains in its Title 3 some rules and standards on accommodation, recreational facilities, and food and catering services on board. In addition, in Title 4 of MLC, 2006 we can find Regulations and standards which have a direct incidence on the quality of the medical care to which seafarers are entitled, both on board and in land, when they stop over on some foreign port. These Regulations also include the first aid kit on board and the demand of an infirmary inside the vessel when trips of over 3 days are made and 15 or more people are on board.

When the situation requires the patient to be hospitalised, the MLC, 2006 clearly establishes who should pay for the medical expenses, not only the hospitalisation expenses but also the expenses for the complete treatment, the medicines, therapies and necessary prosthesis. Likewise, the time during which the ship-owner should continue paying the salary of sick or injured seafarers for causes not attributed to them is regulated.

Moreover, Title 2 of MLC, 2006, in the issues related to working hours and rest hours, salaries and repatriation, seafarers health is also being protected since the lack of the appropriate rest, anguish and concern for a non-paid salary or for a family remittance that could not be sent, as well as the uncertainty of the return to home constitute stress factors, which, as could be certified in scientific studies, damage the emotional health of seafaring people, which can be reflected in their physical health if said psycho-social factors are not controlled in time.

From the many summaries available in the Book of Abstract of the International Maritime Health Symposium No. 13 made in Bergen, Norway from June 23 to 26, 2015, we can mention the summary of Dr. Maria Jeżewska, from the Maritime and Tropical Medicine Institute, Gdynia, Poland, where the following is asserted: "The early research of the quality of life of the seafarers included objective determinants such as: isolation, weather, sea risks, a vessels technical conditions, etc. Much later the subjective determinants were taken into consideration such as: life style, family life satisfaction, diet, relaxation, sleeping habits, etc."

Also the summaries of Dr. Karl IW Forsell, Helena Ericsson, Ralph Nilsson, Eva Andersson, Bengt Jarvholm, Monica Lundh of the Department of Environmental and Work Medicine of the Universities of Gothenburg and Umea, Sweden and the University of Technology, Navigation and Marine Technology in Gothenburg, Sweden, respectively, which introduction establishes the following: "the working environment may be assessed by its safety climate and physical, chemical and psychosocial exposures. There are only a few publications in this field for seafarers. Seafarers are more prone to lethal accidents, ischaemic heart disease and cancer, to which work environmental factors may contribute."

A relevant aspect of MLC, 2006 , is constituted by the fact that it is an international legal body in constant evolution. A clear example of this are the first amendments to the MLC, 2006, with respect to the obligation of demanding the ship-owner the constitution of a financial warranty to guarantee the repatriation, which were adopted in April 2014 at the meeting of the Special Tripartite Committee for the MLC, 2006.

The most important thing to mention is the work of the Special Tripartite Committee (Article XIII of the Convention) 
which, upon identifying a problem derived from the omission in the text, with which the due compliance with Rule 2.5 was affected, they proposed to clear it up, thus amending Part $A$ of the Code of the Maritime Labour Convention, 2006, incorporating Standard A2.5-2, not only to include the detailed procedure or the correct form to execute Rule 2.5, but also the scope of the financial guarantee was increased upon incorporating the term "abandonment of seafarers", which includes both repatriations and the non-payment of salaries for more than 2 months and the failure to provide the correct supply to the vessel (lack of food, drinking water, housing, fuel, medicines). As a result thereof, Part B of the Code was amended upon incorporating Guideline B2.5-3, a new Annex to the Code was created, Annex A2-1, and Annexes A5-I, A5-II and A5-III were amended to keep the consistency with the new provisions.

These first amendments to the MLC, 2006, also included improvements to Rule 4.2, about the Responsibility of the Ship-owner for the events of diseases, injuries or deaths of seafarers as a result of their work in the vessel. Both amendments came into force in January 17, 2017.

In February 2016, the Special Tripartite Committee approved new amendments to the MLC, 2006, which shall come into force 2 years and a half later. Said new amendments pretend to reinforce the efficiency in the observance of Rules 4.3, in order to eliminate the harassment and intimidation on board; and Rule 5.1, regarding to the intention of extending the validity of the Maritime Labour Certificate up to 5 months for the purposes of providing time for the issue of the new Maritime Labour Certificate, once the corresponding inspection has been satisfactorily passed. Also, the possibility of the incorporation of the DIM or Identity Document of Seafarers (reviewed) 2003 (ILO Num. 185) was discussed.

For all the above we can conclude that the MLC, 2006 could be considered as a complement to the SOLAS Convention and an unconditional ally of the International Maritime Health Association. 
